Is Autonomy-Supportive Parenting Beneficial Only to Adolescents With an Autonomous Personality? Two Meanings of Goodness of Fit

Author(s): Elien Mabbe, Bart Soenens, Maarten Vansteenkiste and Sarah De Pauw

Source: Merrill-Palmer Quarterly, July 2020, Vol. 66, No. 3 (July 2020), pp. 308-338

Published by: Wayne State University Press

Stable URL: https://www.jstor.org/stable/10.13110/merrpalmquar1982.66.3.0308

JSTOR is a not-for-profit service that helps scholars, researchers, and students discover, use, and build upon a wide range of content in a trusted digital archive. We use information technology and tools to increase productivity and facilitate new forms of scholarship. For more information about JSTOR, please contact support@jstor.org.

Your use of the JSTOR archive indicates your acceptance of the Terms \& Conditions of Use, available at https://about.jstor.org/terms 


\title{
Is Autonomy-Supportive Parenting Beneficial Only to Adolescents With an Autonomous Personality? Two Meanings of Goodness of Fit
}

Elien Mabbe, Bart Soenens, Maarten Vansteenkiste, and Sarah De Pauw Ghent University

\begin{abstract}
Although autonomy-supportive parenting yields manifold benefits for adolescents' development, there is a dearth of research addressing the question of whether adolescents reap the benefits of this parenting style, irrespective of their personality. Accordingly, this study examined whether associations between perceived maternal autonomy support and adolescent well-being depend on adolescents' dispositional motivational orientations. Further, we examined whether associations between perceived maternal autonomy support and wellbeing are accounted for by adolescents' subjective experiences of goodness of fit. A multi-informant three-wave longitudinal study ( $N=198$ at T1, $51 \%$ female, $M$ age $=15$ years) was used, allowing for an analysis of the associations both at the level of between-person differences and within-person changes. Adolescents' motivational orientations did not moderate associations between maternal autonomy support and well-being. Multilevel structural equation modeling showed that experiences of goodness of fit played an intervening role in associations between maternal autonomy support and adjustment. The discussion focuses on different meanings of the goodness-of-fit concept.
\end{abstract}

Research increasingly demonstrates that autonomy-supportive parenting, which refers to parents' support of children's volitional functioning, is related to positive developmental outcomes in children and adolescents (Joussemet, Landry, \& Koestner, 2008; Soenens, Deci, \& Vansteenkiste, 2017). Autonomy support refers to the degree to which parents create conditions for adolescents

Elien Mabbe, Bart Soenens, and Maarten Vansteenkiste, Department of Developmental, Personality and Social Psychology; and Sarah De Pauw, Department of Special Needs Education.

Address correspondence to Elien Mabbe, Department of Developmental, Personality and Social Psychology, Ghent University, H. Dunantlaan 2, 9000 Ghent, Belgium. Phone: 32 (0)9 264 64 15. E-mail: Elien.Mabbe@UGent.be. 
to experience a sense of choice and volition (i.e., the experience of wanting to engage in behavior rather than being pressured to do so; Grolnick, Ryan, \& Deci, 1991; Soenens et al., 2007). Autonomy-supportive socialization figures make use of a variety of parental practices to promote such volitional functioning, including the adoption of adolescents' frame of reference, the provision of desired degrees of choice, the encouragement of initiative and personal exploration, and the communication of a meaningful rationale when choice is constrained.

Although autonomy-supportive parenting is assumed to be beneficial for developmental outcomes at any age, it has been examined particularly in adolescence because this is a developmental period in which autonomyrelevant developmental tasks (e.g., renegotiation of parent-child relationship and identity formation) are prominent (Soenens, Vansteenkiste, \& Beyers, 2019). An extensive body of research has shown that autonomy-supportive parenting, particularly when perceived by the adolescent, is related to a plethora of adaptive outcomes, including better quality of study motivation (Grolnick et al., 1991), higher well-being, and better emotion regulation (Roth, Assor, Niemiec, Ryan, \& Deci, 2009). Evidence for the adaptive outcomes of autonomy support was obtained in cross-sectional studies but also in longitudinal (e.g., Aunola, Viljaranta, Lehtinen, \& Nurmi, 2013; Van der Giessen, Branje, \& Meeus, 2014) and experimental (e.g., Grolnick, Gurland, DeCourcey, \& Jacob, 2002) studies. A meta-analysis by Vasquez, Patall, Fong, Corrigan, and Pine (2016) confirmed that there is a systematic association between autonomy-supportive parenting and adolescents' quality of motivation and well-being.

In self-determination theory (SDT; Deci \& Ryan, 2000; Vansteenkiste, Niemiec, \& Soenens, 2010), autonomy-supportive parenting is believed to have these systematic positive effects on adolescents' development because it contributes to the satisfaction of three basic psychological needs - that is, the needs for autonomy, competence, and relatedness. The need for autonomy refers to the experience of volition and psychological freedom in one's acting, thinking, and feeling. The need for competence refers to the experience of being able to develop skills and to deal effectively with challenges. The need for relatedness refers to the experience of reciprocal care and love in relationships with significant others. Clearly, autonomysupportive parents create conditions in which children can feel a sense of authenticity and ownership of their actions, thoughts, and feelings (autonomy). Through the encouragement of initiative and the provision of choice, these parents also convey a sense of trust in the child's emerging skills (competence). Because autonomy-supportive parents take the child's frame of reference, children are also likely to feel understood (resulting in a sense of relatedness). Consistent with the claim that these needs 
represent universal nutriments for psychological growth (Deci \& Ryan, 2000; Ryan \& Deci, 2000), studies in different age groups and cultures have shown that satisfaction of these three needs is related to well-being and to better psychosocial adjustment (Sheldon, Cheng, \& Hilpert, 2011). Further, as maintained in the theory, psychological need satisfaction plays an intervening role in the associations between autonomy-supportive parenting and adaptive developmental outcomes (Costa, Cuzzocrea, Gugliandolo, \& Larcan, 2016; Grolnick et al., 1991).

The convincing and systematic findings regarding the salutary effects of autonomy-supportive parenting, as well as its presumed role in nurturing universally critical psychological needs, raise questions about the role of individual differences in these effects (Ryan, Soenens, \& Vansteenkiste, 2019; Soenens, Vansteenkiste, \& Van Petegem, 2015). Although autonomysupportive parenting is generally related to better outcomes, there is still variation in the extent to which this is the case. Vasquez et al.'s (2016) meta-analysis showed that there is substantial heterogeneity in effects of autonomy-supportive parenting on motivation and well-being. This finding raises the question of whether all adolescents benefit from perceived autonomy support to the same extent. Or does adolescents' personality play a role? To address these questions, we turn to a discussion of the notion of goodness of fit, which is key to understand the interplay between parenting and child characteristics in the prediction of child outcomes (Thomas, Chess, \& Birch, 1968).

\section{Goodness of Fit as a Match Between Parenting and Adolescents' Characteristics}

The goodness-of-fit concept involves the idea that adaptive child development is a function of an adequate fit between child and environmental characteristics (Thomas et al., 1968). Thomas and Chess (1977) emphasized that the reciprocal interaction between the child and the environment exerts a major influence on children's adjustment. With regard to parenting, the goodness-of-fit concept entails the view that parenting should be tailored to a child's unique characteristics to assure healthy psychological development (De Pauw \& Mervielde, 2010). Adjustment problems are more likely to occur when there is a mismatch between a child's characteristics and parental expectations or practices. For example, a very active and outgoing child is more likely to develop problems when raised by timid parents, who have stronger expectations for the child to be quiet.

The notion of goodness of fit is often invoked as an explanation to account for interactions between parenting and child characteristics, with 
child characteristics typically operationalized as individual differences in personality or temperament (e.g., Manders, Scholte, Janssens, \& De Bruyn, 2006; Van Leeuwen, Mervielde, Braet, \& Bosmans, 2004). For example, van Aken, Junger, Verhoeven, van Aken, and Dekovic (2007) found that children with a difficult temperament exhibited more externalizing problems when exposed to controlling (i.e., autonomy-suppressing) parenting. They concluded that the combination of a difficult temperament and controlling parenting violates the goodness-of-fit principle, and that this mismatch leads to maladjustment.

In principle, the notion of goodness of fit could be interpreted in a strict and literal fashion. Like a key that fits only one lock, a particular parenting style would be adaptive only for children with exactly matching adolescent characteristics. Although few scholars, if any, support this view, such a literal interpretation of the goodness-of-fit idea may open the door for a relativistic position on parenting processes (Soenens et al., 2015). No parenting style (including autonomy support) would have systematic adaptive value, and the effects of parenting styles would always depend fully on the presence of particular child characteristics.

Applied to the concept of autonomy-supportive parenting, such a strict interpretation of goodness of fit would imply that autonomy-supportive parenting would be adaptive only for children dispositionally oriented towards autonomy. In SDT, personality-based individual differences in autonomy are conceptualized as causality orientations, which reflect relatively stable individual differences in the way people interpret events and in the way they regulate their behavior (Deci \& Ryan, 1985). Ryan and Deci (2017) define causality orientations as "characteristic adaptations reflecting people's propensities to orient to different motivationally relevant aspects of situations." Individuals with an autonomous causality orientation tend to interpret situations as informational and tend to regulate their behavior on the basis of personal interests and authentic values. This orientation can be contrasted with a controlled causality orientation, which is characteristic of people who tend to interpret events as threatening and evaluative and who regulate their behavior on the basis of internal or external pressures. If a literal match would be required for autonomy support to yield benefits, parental autonomy support would be related positively to well-being only among adolescents scoring high on an autonomous orientation and not (or even negatively) among adolescents scoring high on a controlled orientation.

Much like the relativistic perspective on autonomy-supportive parenting, also the universalistic perspective could be interpreted very strictly (Soenens et al., 2015). In the case of an extreme universalistic perspective, there would be no room for moderation whatsoever, and 
all adolescents would be assumed to benefit from autonomy-supportive parenting to the same degree. Importantly, SDT does not represent such a strict universalistic perspective. Instead, it represents a more moderate view according to which individual differences may alter the strength (but not the presence or absence) of the association between parenting and developmental outcomes (Deci \& Ryan, 1987). Specifically, in SDT, the notion of sensitization (Moller, Deci, \& Elliot, 2010) postulates that people with a history of need-satisfying experiences become more sensitive to the benefits of new potentially need-satisfying events. It can be assumed that adolescents dispositionally oriented towards autonomy have encountered more need-satisfying experiences in their past and may even proactively elicit such experiences in the present (Reeve, 2013)-that is, experiences that make them more sensitive for future need-satisfying experiences. Conversely, adolescents with a more controlled orientation are likely to generally experience less need satisfaction and may become less sensitive to contextual support for their needs (including autonomy-supportive parenting). Technically, a pattern of sensitization will be expressed in a difference in strength of the association between an autonomy-supportive parenting style and positive outcomes, with adolescents scoring higher on an autonomous orientation deriving greater benefits from autonomy support and with adolescents scoring higher on a controlled orientation deriving fewer of these benefits.

\section{Goodness of Fit as a Subjective Experience}

In addition to considering the goodness-of-fit principle as a rather static principle reflecting the degree of objective match between a parent's style and an adolescent's personality, we also suggest another, more dynamic interpretation. In their original writings already, Thomas and Chess (1977) argued that goodness of fit should not be regarded as a homeostatic principle but as a homeodynamic one. That is, the notion conveys the idea that parents continuously try to attune their parenting behavior to their children's needs, thereby seeking optimal synchronization. Ideally, these tailoring attempts lead children to experience that their parents understand their personality characteristics and consider these characteristics when interacting with the child. The notion that people can differ in their subjective experience of goodness of fit was underscored by Seifer et al. (2014, p. 87) when they noted that "caregivers and children interpret and experience the objective degree of fit very differently." Whereas Seifer et al. (2014) focused on parents' subjective experiences of fit, in this study, we focus on adolescents' perception of fit because adolescents' perceptions 
of parent-child interactions ultimately affect developmental outcomes (Soenens et al., 2015).

On the basis of SDT, we argue that autonomy-supportive parenting is particularly likely to give rise to adolescents' subjective feelings of goodness of fit. This is because a key feature of autonomy support is parents' curiosity and receptivity for the children's frame of reference (Grolnick, Deci, \& Ryan 1997; Mageau, Sherman, Grusec, Koestner, \& Bureau, 2017; Vansteenkiste \& Soenens, 2015). Because autonomy-supportive parents are genuinely interested in the child's view, they are better capable of attuning their parenting practices to the child's perspective. For instance, because they provide choices and explain rules with the child's perspective and personality in mind, these choices and explanations are personally meaningful to the child. As a consequence of such attunement, children are likely to experience that their parents have a pretty accurate picture of who they are and that, as much as possible, they consider the child's perspective. Thus, it can be expected that autonomy-supportive parenting is related to a stronger subjective sense of goodness of fit in adolescents that, in turn, is related to well-being.

\section{The Present Study}

The overall aim of this study is to examine the relevance of the concept of goodness of fit to autonomy-supportive parenting, thereby distinguishing between two meanings of this concept. First, based on the notion that goodness of fit refers to the degree of match between the environment and the child's characteristics, we examine whether associations between autonomy-supportive parenting and well-being depend on adolescents' causality orientations. We specifically consider the possibility that the causality orientations can affect the degree to which autonomy-supportive parenting is related to adolescent well-being such that the associations between autonomy-supportive parenting and well-being are more pronounced among adolescents scoring high on the autonomous orientation and attenuated among adolescents scoring high on the controlled orientation.

Second, we also consider goodness of fit from a more subjective perspective. We will examine whether perceived fit mediates the association between autonomy-supportive parenting and well-being. We hypothesize that autonomy-supportive parenting will relate positively to a subjective sense of goodness of fit in adolescents and that this subjective experience of fit will play an intervening role in associations between autonomy-supportive parenting and well-being.

Because the two research questions addressed in this study deal with dynamic intervening processes (i.e., moderation by causality orientations 
and mediation by goodness of fit), it was deemed important that we examine these processes by using a longitudinal design. Indeed, processes of moderation and mediation essentially deal with processes of change. More specifically, it is increasingly argued that the level of intraindividual change is a particularly important and relevant level to chart such developmental processes (Keijsers, 2016). For instance, the assumed moderating role of an autonomous causality orientation may manifest not only at the level of between-person differences between adolescents but also at the level of within-person change in adolescents: Adolescents high on an autonomous orientation may be particularly sensitive to an experienced increase in autonomy-supportive parenting relative to the degree of parental autonomy support they experienced before. That is, to the extent that these adolescents perceive their mothers' autonomy-supportive parenting to increase compared to before, they would display an even stronger increase in wellbeing when compared to adolescents low in the autonomous orientation. Similarly, the explanatory role of goodness of fit is expected to manifest both with respect to differences between adolescents (i.e., between-person level), as well as with respect to the fluctuations within a given adolescent (i.e., within-person level of change). That is, the very reason why an intraindividual increase in experienced parental autonomy support would go hand in hand with intraindividual increases in well-being is because it would entail an intraindividual increase in goodness of fit. To put it less technically, because adolescents perceive their mothers as more autonomy supportive than before, they would experience a stronger sense of subjective fit and, hence, a higher sense of well-being than before. Overall, to examine our research questions dynamically, we relied on a longitudinal design and relied on multilevel analyses to differentiate between associations at the between-person level and at the level of intraindividual change.

\section{Method}

\section{Participants and Procedure}

Participants were Belgian, Dutch-speaking adolescents and their parents: mean age at Time $1(\mathrm{~T} 1)=14.89$ years, $S D=0.88$, range $13-17,51 \%$ female. Almost all adolescents $(99 \%)$ lived in intact families (i.e., with the parents being married or living together). Most families consisted of two children $(51 \%)$, followed by families with three children $(29 \%)$, families with one child (10\%), and families with four children or more $(10 \%)$. All adolescents were enrolled in a high-school program, with $67 \%$ following an academic track and with $33 \%$ following a technical or vocational track. Mothers' mean age was 45 years ( $S D=3.20$, range $37-53$ years). On a 
6-point scale, their mean educational attainment was $4.11(S D=1.15)$, indicating an average of 15 years of education.

In October 2012, 198 families were recruited as part of an undergraduate course in developmental psychology in which students were asked to invite two adolescents living in intact families (who were not relatives or close friends of the student) to participate in the study. We chose to recruit intact families because this study was part of a broader project aiming to examine the interplay between maternal and paternal parenting. Students were trained to approach potentially interested families. They briefly explained the purpose of the study and asked adolescents to assent to participate. Adolescents signed an informed consent when they decided to participate in the study. In addition, parents were asked to provide active consent and to also complete a questionnaire themselves. Questionnaires with detailed information and instructions were provided by the undergraduate students during a home visit and were completed in the presence of the student who recruited the family. The first page of the instructions emphasized that participation was voluntary and data would be treated confidentially. After completing the questionnaires, participants put their questionnaires in separate, sealed envelopes and returned these envelopes to the student, who, in turn, returned them to the researchers. Families were again contacted by e-mail in June 2013 (Wave 2) and June 2014 (Wave 3) to participate in the study. At T2, 144 adolescents and mothers participated again, while, at T3, 123 adolescents and mothers participated again. Analysis of the missing values showed that those missing were completely at random: Little's missing completely at random $(\mathrm{MCAR})$ test, $\chi^{2}(195)=189.6, p>.05$. Accordingly, full-information maximum likelihood (FIML) in Mplus 7.0 (Muthén \& Muthén, 1998-2012) was used to estimate missing values.

\section{Measures}

All instruments have been used successfully in past research with Dutchspeaking populations or were developed in Dutch for the purpose of this study. All variables were assessed at each wave, except for the causality orientations (assessed at Waves 1 and 2 only), which were assumed to reflect relatively stable individual differences. Therefore, we relied on only the scores for the causality orientations measured at T1. Cronbach's alphas of the scales are reported in Table 1.

Autonomy-supportive parenting (assessed at each wave). Both mothers and adolescents were administered the Dutch version (Soenens et al., 2007) of the Autonomy Support Scale of the Perceptions of Parents Scale (POPS; Grolnick et al., 1991). The seven items (e.g., "My mother allows me to 


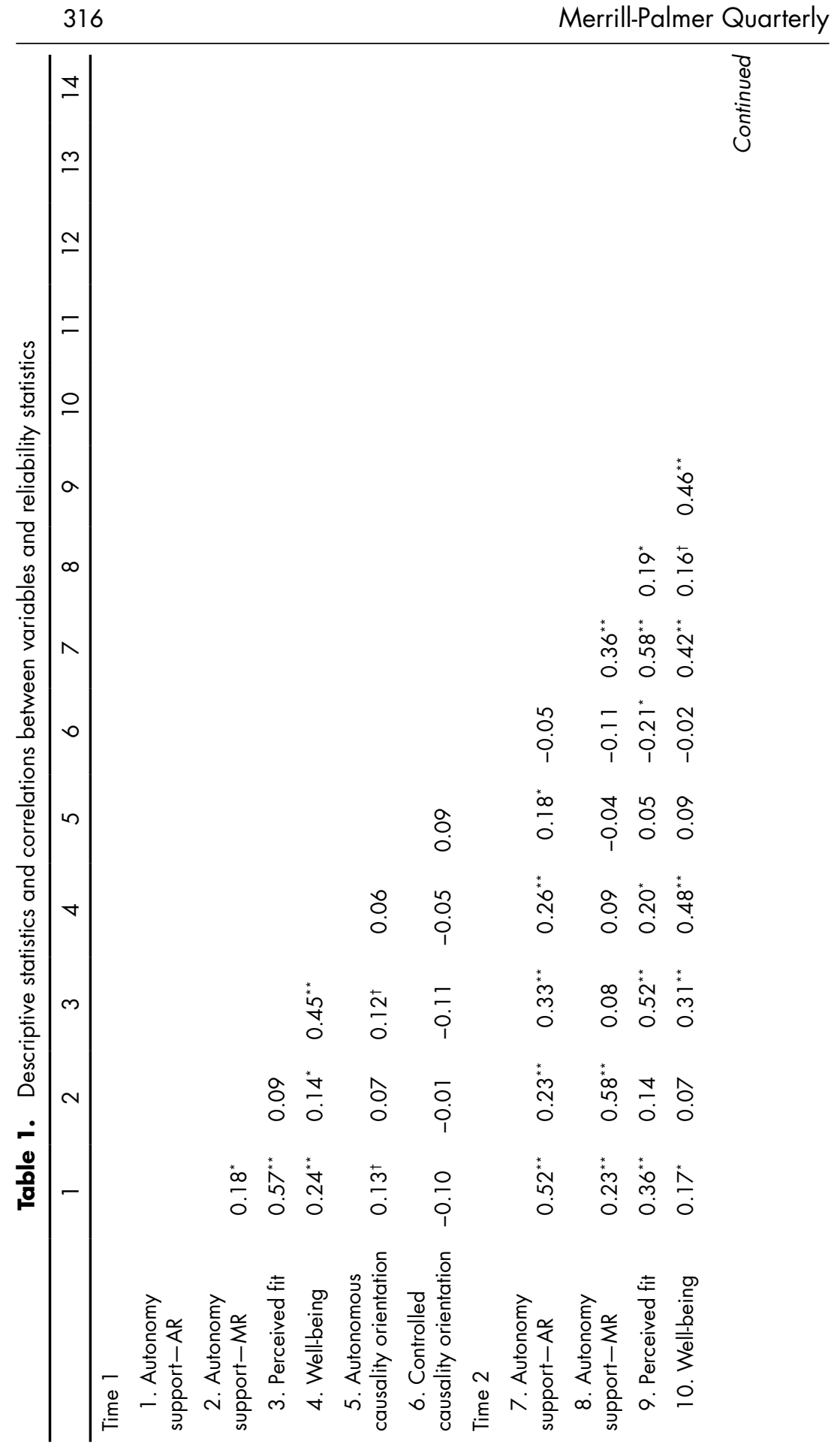




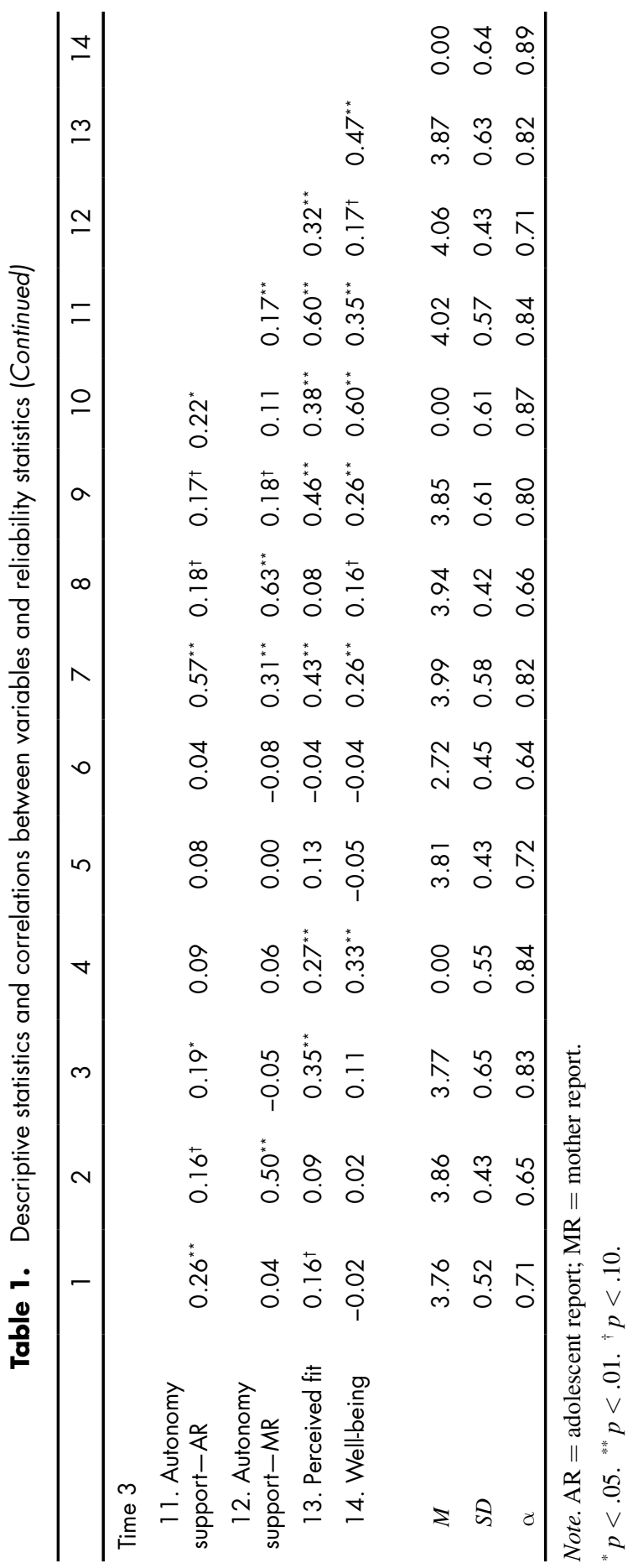


decide things for myself") were scored on a 5-point Likert scale, ranging from 1 (completely not true) to 5 (completely true). We focused on mothers because they continue to represent key socialization figures in early to middle adolescents' lives (Bornstein, 2015). To avoid problems associated with shared method variance, the study includes both mother reports and adolescent reports of maternal autonomy support. When the association between autonomy support and perceived goodness of fit would be obtained when using only adolescent reports of both constructs, one might argue that this association exists only in the eye of the beholder. If, in contrast, this association emerges across informants of parenting, it indicates a more substantive phenomenon.

Causality orientations (using assessment at Wave 1 only). Adolescents completed the short Dutch version (Soenens, Berzonsky, Vansteenkiste, Beyers, \& Goossens, 2005) of the General Causality Orientations Scale (GCOS; Deci \& Ryan, 1985). The questionnaire consists of 12 vignettes, starting with a description of an everyday-life situation (e.g., "You are thinking of making a new study choice. Your most important consideration is likely to be ..."). Because some of the situations in the original GCOS were relevant only to adults and not to adolescents, these situations were slightly changed to be more appropriate for an adolescent population. These situations are followed by items reflecting an autonomous orientation (e.g., "How interested you are in this new study domain") and a controlled orientation (e.g., "Whether there are good possibilities for employment after this study"). Although the original GCOS contains items tapping into a third orientation (the impersonal orientation), this orientation was deemed less relevant for our research purposes and was not included. Adolescents rated items on both motivational orientations on a 5-point Likert scale ranging from 1 (completely not true) to 5 (completely true). Because, to the best of our knowledge, this is the first time the GCOS was used in an adolescent sample, we examined its validity by relating both orientations to scores on the Big Five traits, which were measured in this study at T1 with the Hierarchical Personality Inventory for Children (HiPIC; Mervielde \& De Fruyt, 1999). Specifically, we inspected whether associations in our sample of adolescents would be similar to associations obtained with adults. Consistent with research on adults (Olesen, 2011; Olesen, Thomsen, Schnieber, \& Tonnesvang, 2010), we found that the autonomous causality orientation was correlated positively with extraversion $(r=.22, p<.01)$, agreeableness $(r=.24, p<.01)$, and openness to experience $(r=.33, p<.01)$. In addition, the autonomous orientation was related positively to conscientiousness $(r=.24, p<.01)$ and negatively to neuroticism $(r=-.17, p<.05)$. Also consistent with research on adults, the controlled causality orientation was related negatively to agreeableness $(r=-.31, p<.01)$. 
Overall, these associations are consistent with findings in adult samples and with the theoretical assumption that an autonomous orientation represents a more resilient, mature type of personality functioning than does a controlled orientation (Deci \& Ryan, 1985). Furthermore, the stability of the causality orientations across a 1-year interval was examined. Evidence for substantial cross-temporal stability was found, with the stability correlations of autonomous and controlled causality orientation between the first two waves being $.53(p<.001)$ and $.46(p<.001)$, respectively. These stability coefficients are similar (in terms of effect size) to stability coefficients reported for other personality traits (e.g., the Five Factor Model dimensions of personality) in this age period (i.e., early to middle adolescence; Klimstra, Hale III, Raaijmakers, Branje, \& Meeus, 2009).

Perceived fit (assessed at each wave). We developed a new sixitem scale for this construct, which was administered to the adolescents. The formulation of the items was derived directly from the conceptual definition of perceived goodness of fit used in this study, resulting in a set of items with high face validity. Three items refer to the extent to which adolescents feel like their mother knows their personality (i.e., "I feel that my mother really knows and understands my personality," "I feel that my mother knows well what my personality is like," and "My mother has a different view on my personality than I do," reverse scored). The other three items refer to the extent to which adolescents feel like their mother considers their personality when interacting with the child (i.e., "I feel that my mother takes into account my personality," "My mother adjusts her behavior to my personality," and "My mother makes me do things that really do not fit my personality," reverse scored). The items were scored on a 5-point Likert scale, ranging from 1 (completely not true) to 5 (completely true).

A principal components analysis on the items of this scale clearly pointed towards a one-component solution, with only one component having an eigenvalue larger than 1 (and explaining 56\%, 53\%, and 56\% of the variance at T1, T2, and T3, respectively). All items had substantial loadings on this component, with loadings ranging between .54 and .84 at T1, between .55 and .89 at T2, and between .51 and .88 at T3. Because autonomy-supportive parenting and perceived goodness of fit may appear to be closely related concepts, concerns may be raised regarding adolescents' ability to clearly distinguish between both constructs. We performed a confirmatory factor analysis (CFA) on the items from the scales for adolescent-perceived autonomy-supportive parenting and goodness of fit to see whether these items are measuring separate constructs. At each wave, we conducted two CFAs, with one model withholding only one global factor and with another model withholding two distinct factors. At each of the three waves, a two-factor model provided a significantly better fit to 
the data than did a one-factor model, $\Delta \chi^{2}(1)=42.50, p<0.001 ; \Delta \chi^{2}(1)$ $=106.64, p<0.001$, and $\Delta \chi^{2}(1)=166.24, p<0.001$, indicating that adolescents do perceive a clear distinction between mothers' engagement in autonomy-supportive practices and experiences of goodness of fit. Finally, to further document the validity of this newly developed scale, we also examined associations between the scale and the Big Five traits, thereby again using scores on the HiPIC obtained at T1. Consistent with the prediction that it is easier for mothers to consider adolescents' personality when adolescents score high on adaptive and mature personality traits, we found that the scale for goodness of fit was related positively to agreeableness $(r$ $=.32, p<.001)$, conscientiousness $(r=.26, p<.001)$, and emotional stability $(r=.18, p<.05)$. An alternative explanation to consider is that adolescents with more stable and agreeable personalities generally perceive their relations with others, and their mother in particular, more positively.

Well-being (assessed at each wave). Adolescents completed three scales: the five-item Global Self-Worth subscale (e.g., "I am often disappointed with myself," reverse scored) of the Self-Perception Profile for Adolescents (SPPA; Harter, 1988; Wichstrom, 1995), the five-item Satisfaction with Life Scale (SWLS; Diener, Emmons, Larsen, \& Griffin, 1985; e.g., "I am satisfied with my life") and the seven item Subjective Vitality Scale (Ryan \& Frederick, 1997). The SWLS and the Subjective Vitality Scale were rated on a 5-point Likert scale ranging from 1 (completely not true) to 5 (completely true). The Self-Worth Scale was rated on a 4-point Likert scale ranging from 1 (completely not true) to 4 (completely true). A composite score was created by standardizing these measures of well-being and calculating the mean of these three scales. This approach was justified by the observation that correlations between the three measures within each wave were high, ranging .43-.69.

\section{Plan of Analysis}

To examine the main hypotheses, multilevel structural equation modeling (MSEM) was performed using Mplus 7.0 (Muthén \& Muthén, 1998-2012). The comparative fit index (CFI), the root mean squared error of approximation (RMSEA), and the standardized root mean square residual (SRMR) were selected to evaluate model fit. According to $\mathrm{Hu}$ and Bentler (1999), combined cutoff values close to 0.95 for $\mathrm{CFI}$ and close to 0.06 for RMSEA and 0.09 for the SRMR indicate good fit.

In the multilevel structural equation modeling analyses, the three measurement occasions (Waves 1-3) represent Level 1 (i.e., the withinperson level), and these waves are nested within participants, representing Level 2 (i.e., the between-person level; Mackinnon, Kehayes, Clark, Sherry, 
\& Stewart, 2014; Preacher, Zyphur, \& Zhang, 2010). For all models tested (except for the models testing interactions at the between-person level, see later), this multilevel approach was used to analyze the longitudinal data. In these analyses, the total variance is decomposed into variance at the between level and variance at the within level. Variance at the between-person level refers to variance around the mean of all persons over the years (e.g., the degree to which one adolescent perceives more autonomy support over the years than another adolescent). Variance at the within-person level refers to variance around the mean of one person over the years (e.g., the degree to which an adolescent perceives more autonomy support in a given year relative to this adolescent's overall level of perceived autonomy support over the years).

An initial structural multilevel model tested the direct associations between maternal autonomy-supportive parenting and well-being both at the level of between-person differences and at the level of within-person change. This model includes only the main effect of autonomy-supportive parenting on well-being at both levels. Associations significant at the between-person level indicate that participants who perceive more autonomy-supportive parenting relative to other participants also report more well-being. Associations significant at the within-person level indicate that, when autonomy-supportive parenting increases in a given year relative to participants' overall autonomy support over the years, well-being within individuals also increases (relative to their overall levels of wellbeing). As such, associations at the within-person level reflect correlated change within adolescents' functioning. Models were tested separately for adolescent and mother reports of maternal autonomy support.

The moderating role of the causality orientations in effects of autonomy-supportive parenting on well-being are tested both at the level of between-person differences and at the within-person level. Analyses will be performed separately for the autonomous and controlled causality orientations and again separately for adolescents' and mothers' reports of autonomy support. To test the moderating role of the causality orientations at the level of within-person differences, cross-level interactions will be conducted. Such cross-level interactions address the question of whether the strength of associations at the intraindividual level depend on interindividual differences in causality orientations. For instance, is the within-person association between autonomy-supportive parenting and well-being more pronounced among adolescents with a higher score on an autonomous orientation (relative to other adolescents)? For this purpose, we will first inspect whether the random slopes of the within-person associations are significant, which would mean that there is variance in the strength of the within-person associations between autonomy-supportive parenting 
and well-being. If this is the case, we can test whether interindividual differences in the causality orientations can explain part of this variance. In order to test the moderating role of the causality orientations at the level of between-person differences, interaction analyses will be conducted within each of the three waves separately. Although we tried to test these interaction effects at the between-person level also within a multilevel framework, these models did not converge. After consulting statistical experts, it was decided to test the moderating role of interindividual differences in causality orientations within each of the separate waves by using straightforward regression models.

In a final analysis, we will examine whether perceived goodness of fit mediates associations between autonomy-supportive parenting and wellbeing, As depicted in Figure 1, this mediation model examines the intervening role of goodness of fit simultaneously at the within-person level and between-person level. Mediation at the between-person level (which is shown in the top half of Figure 1) involves the question of whether associations between interindividual differences in autonomy-supportive parenting and well-being are accounted for by interindividual differences in goodness of fit. Mediation at the within-person level (which is shown in the bottom half of Figure 1) involves the question of whether associations between intraindividual fluctuations in autonomy-supportive parenting and wellbeing are accounted for by intraindividual fluctuations in goodness of fit.

\section{Results}

\section{Preliminary Analyses}

Means, standard deviations, and correlations between the study variables are presented in Table 1 . To determine whether scores on the study variables that were assessed at each wave varied by time, gender, and age, a repeated-measures multivariate analysis of covariance (MANCOVA) was conducted (with time as a within-subjects predictor, with gender as a categorical independent variable, and with age as a continuous covariate). There was an overall multivariate effect for gender, Wilks's $\lambda=0.88, F(4$, $102)=3.25, p=.01$, and for age, Wilks's $\lambda=0.89, F(4,102)=3.12, p=$ .02 , but not for time, Wilks's $\lambda=0.93, F(8,98)=0.98, p=.49$. Follow-up univariate analyses revealed that girls reported lower well-being than did boys, which was an effect that was not moderated by time or age. Follow-up analyses also revealed that age at Wave 3 was related to autonomy-supportive parenting reported by the mother. Mothers of older adolescents reported more autonomy-supportive parenting $(r=.29, p=.001)$. A univariate analysis of variance was used to determine whether adolescents' scores on 


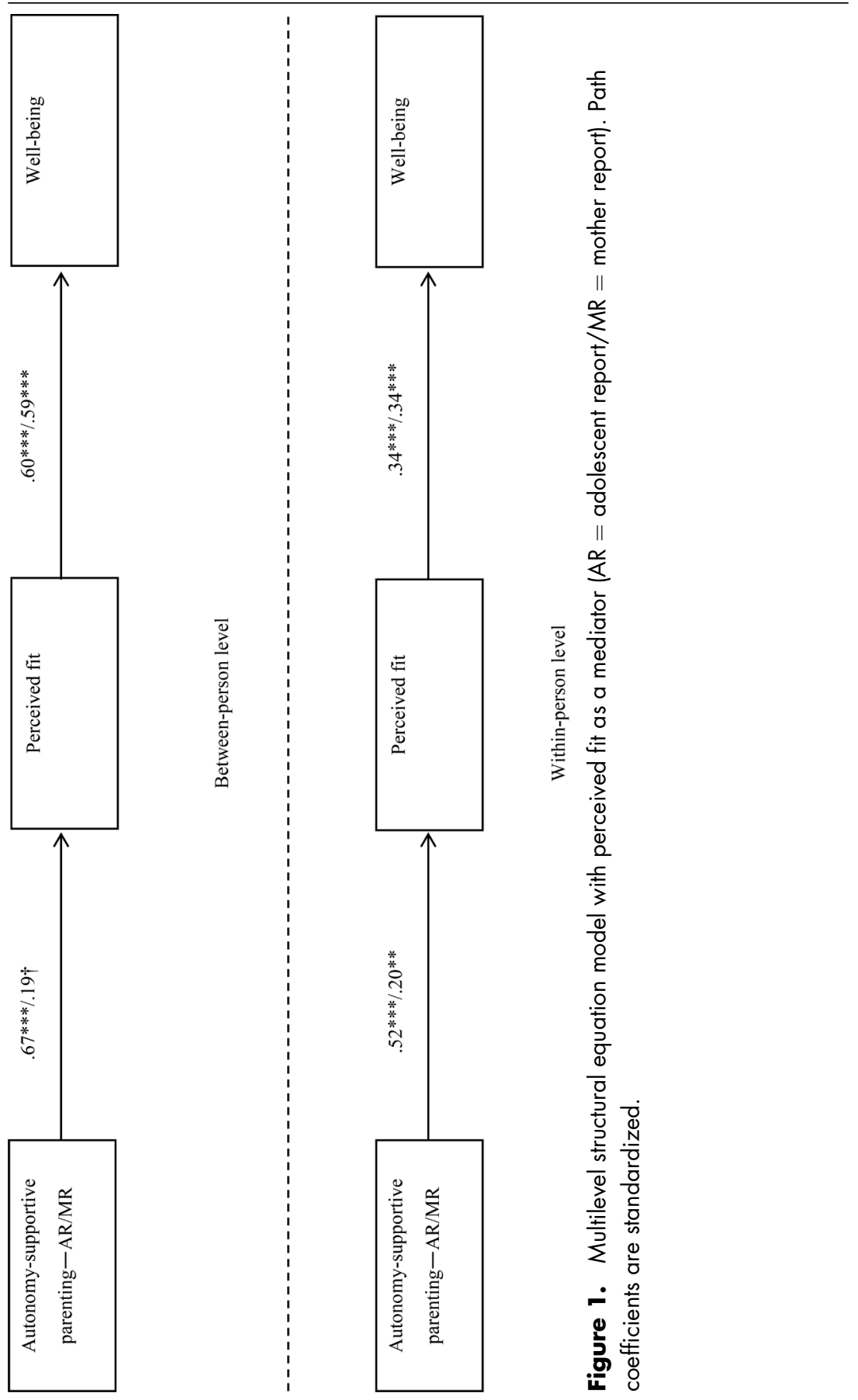


the causality orientations at T1 varied by gender and age. Results showed that girls reported higher scores on the autonomous causality orientation $(M=3.88, S D=.43)$ than did boys $(M=3.73, S D=.44)$. Given these results, we controlled for gender and age in all subsequent analyses.

\section{Primary Analyses}

First, intraclass correlations (ICCs) for all study variables were calculated to examine whether multilevel modeling was appropriate. ICCs shed light on the proportion of the total variance that is due to between-person variation and within-person variation, with the ICC reflecting the percentage of variance located at the between-person level. The ICCs were 49 for perceived fit, .47 for well-being, and .45 for adolescent-reported and .56 for mother-reported autonomy-supportive parenting. This means that, respectively, $49 \%, 47 \%, 45 \%$, and $56 \%$ of the variance in perceived fit, wellbeing, and adolescent-reported and mother-reported autonomy-supportive parenting reflects differences between persons. Conversely, about half of the variance in these constructs represents within-person fluctuations across time (although this part of the variance also includes error variance). Data are suitable for multilevel structural equation modeling when the ICC is above .05 (Preacher et al., 2010).

Testing the moderating role of the causality orientations. As the main effect models are just-identified, these models had by definition perfect fit, so no fit measures are reported. Adolescent-reported autonomy-supportive parenting was associated positively with well-being, both at the betweenperson level $(\beta=.42, p=.00)$ and at the within-person level $(\beta=.24$, $p=.01)$. Mother-reported autonomy-supportive parenting was associated positively with well-being at the between-person level $(\beta=.25, p=.02)$ but not at the within-person level $(\beta=.07, p=.35)$.

Then, we tested the moderating role of the causality orientations in effects of autonomy-supportive parenting on well-being, at the level of between-person differences. We performed analyses separately for the autonomous and the controlled causality orientations and within each of the three waves. Again, we performed these models separately for adolescent and mother reports of autonomy support. Since these models are also just-identified, no fit measures are reported. As shown among the results listed in Table 2, the causality orientations did not moderate any of the between-person effects of autonomy-supportive parenting on well-being.

To examine whether the causality orientations would moderate associations between autonomy-supportive parenting and well-being at the within-person level, we tested cross-level interactions. Again, these analyses were done separately for the autonomous and controlled causality 


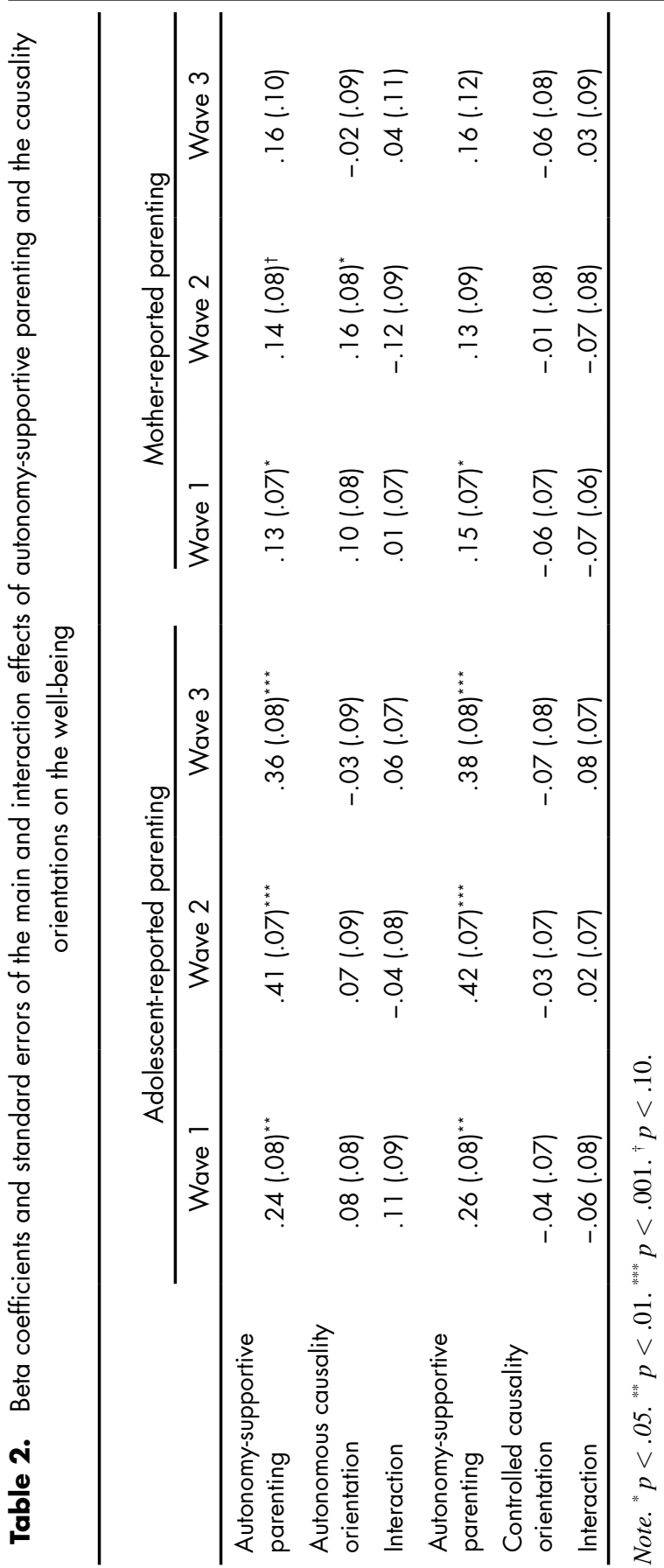


orientations and for adolescent and mother reports of autonomy support. To test whether there were interindividual differences in the strength of the within-person association between autonomy-supportive parenting and well-being, we first inspected whether the random slope of this association was significant. This was the case for adolescent reports of parenting, $B=.51$ (.16), $p=.00$, but not for mother reports of parenting, $B=.66$ (.47), $p=.16$. This finding indicates that the association between withinperson fluctuations in adolescent-reported (but not in mother-reported) autonomy-supportive parenting and within-person changes in well-being is more pronounced in some adolescents than in others. Thus, we could examine the potential moderating role of adolescents' causality orientations only with respect to adolescent reports of parenting.

Neither the cross-level interaction between the autonomous causality orientation and adolescent-reported autonomy-supportive parenting, $B=.25$ (.26), $p=.33$, nor the cross-level interaction between adolescent-reported autonomy-supportive parenting and the controlled orientation, $B=.20$ (.26), $p=.44$, was significant. These findings indicate that the causality orientations were unrelated to differences in the strength of the within-person association between autonomy-supportive parenting and well-being. Said differently, a perceived intraindividual increase in autonomy-supportive parenting contributed positively to an intrapersonal increase in well-being, regardless of adolescents' interindividual differences in the causality orientations.

Overall, these analyses indicate that the causality orientations did not moderate associations between autonomy-supportive parenting and wellbeing, neither at the level of between-person differences nor at the level of within-person (yearly) fluctuations. To put it less technically, to the extent that adolescents perceive or mothers report greater levels of autonomy support, adolescents report greater well-being, regardless of whether adolescents score low or high on the autonomous or controlled orientation. Similarly, to the extent adolescents perceive or mothers report an increase in autonomy support to before, a parallel increase in well-being is reported, which is an effect that was observed regardless of whether adolescents score high or low on the autonomous orientation or controlled orientation.

Testing the intervening role of perceived goodness of fit. The intervening role of perceived goodness of fit was tested in an integrated model (see Figure 1), which included only indirect associations between autonomy-supportive parenting and well-being through perceived goodness of fit. These indirect associations were tested simultaneously at the betweenperson and within-person levels. The significance of indirect effects was tested by using bootstrapped confidence intervals in Mplus (MacKinnon, Lockwood, Hoffman, West, \& Sheets, 2002). 
Model fit was adequate both for the model including adolescent reports of parenting, $\chi^{2}(2)=1.44, \mathrm{RMSEA}=.00, \mathrm{CFI}=1.00, \mathrm{SRMR}=.03$, and for the model including maternal reports of parenting, $\chi^{2}(2)=2.77$, $\mathrm{RMSEA}=.03, \mathrm{CFI}=.99, \mathrm{SRMR}=.00$. Results with adolescent reports of parenting showed that perceived autonomy-supportive parenting was related to perceived fit at both the between-person level $(\beta=.67$, $p=.001)$ and the within-person level $(\beta=.52, p=.001)$. Perceived fit, in turn, was related to well-being at both the between-person level $(\beta=.60$, $p=.001)$ and the within-person level $(\beta=.34, p=.001)$. The indirect effects of autonomy-supportive parenting on well-being (through goodness of fit) were significant both at the level of the between-person differences, $B=.62(.15), p=.001$, and at the level of within-person change, $B=.25$ (.07), $p=.001$. Results with mothers' reports of parenting showed that autonomy-supportive parenting was related to perceived fit at the level of within-person change $(\beta=.20, p=.004)$ but not at the between-person level. However, even at the between-person level, the association was marginally significant $(\beta=.19, p=.096)$. Perceived fit, in turn, was related to well-being at both the between-person level $(\beta=.59, p=.000)$ and the within-person level $(\beta=.34, p=.000)$. The indirect effect of autonomysupportive parenting on well-being (through goodness of fit) was significant at the level of the within-person differences, $B=.14(.07), p=.027$, but not at the level of between-person change, $B=.20(.15), p=.168$.

To examine whether goodness of fit functioned as a full mediator or as a partial mediator in associations between autonomy support and wellbeing, we tested whether direct effects from autonomy support on wellbeing would still be significant after considering the intervening role of goodness of fit. Results showed that, after accounting for perceived fit, the direct effect of adolescent-reported parenting on well-being is no longer significant at the within-person level $(\beta=.08, p=.38)$ nor at the betweenperson level $(\beta=.05, p=.73)$. The direct effect of mother-reported parenting on well-being is also no longer significant at the within-person level $(\beta=.002, p=.97)$ nor at the between-person level $(\beta=.14, p=.10)$.

Overall, the explanatory role of perceived fit in the association between autonomy-supportive parenting and well-being was confirmed in three of the four cases. That is, it applied at the within-person level for both adolescent and mother reports and at the between-person level for adolescent reports. Such findings imply that adolescents' level of experienced fit is a robust explanatory mechanism because it can account for the reason why adolescents who perceive more autonomy support than their peers report more well-being and why fluctuations in experienced or mother-reported autonomy support covary with fluctuations in wellbeing across time. 
Ancillary Analysis

Using multigroup analyses, we tested whether the associations obtained in this study would depend on adolescents' gender. A first multigroup analysis tested the moderating role of gender in the main effects models (autonomy-supportive parenting reported by adolescent or mother predicting well-being). Multigroup analyses revealed that gender did not moderate associations in the structural models $\left(\Delta \chi^{2}=6.03, d f=2, p>.05\right.$, for the model with adolescent-reported autonomy-supportive parenting, and $\Delta \chi^{2}$ $=.05, d f=2, p>.05$, for the model with mother-reported autonomy-supportive parenting). With respect to the mediation models, multigroup analyses also revealed that gender did not moderate associations in the structural models $\left(\Delta \chi^{2}=4.72, d f=3, p>.05\right.$, for the model with adolescent-reported autonomy-supportive parenting, and $\Delta \chi^{2}=2.15, d f=3, p>.05$, for the model with mother-reported autonomy-supportive parenting).

\section{Discussion}

Although an impressive body of research has demonstrated that autonomysupportive parenting is related to beneficial developmental outcomes in adolescents (Joussemet et al., 2008; Soenens et al., 2017), few studies have addressed the question of whether these benefits are limited to adolescents with particular personality characteristics. This study examined the role of adolescents' personality both in terms of an objective match between adolescents' autonomous orientation and autonomy-supportive parenting and in terms of a more subjective experience of goodness of fit.

\section{Goodness of Fit as an Objective Match}

On the basis of Thomas and Chess's (1977) notion of goodness of fit, it could be argued that parental autonomy support is particularly adaptive (or even only adaptive) for adolescents with matching personality characteristics - that is, for adolescents with a strong dispositional inclination towards autonomy. In contrast, parental autonomy support would be less adaptive (or not adaptive at all) for adolescents with a more controlled orientation. This interpretation of the goodness-of-fit principle as an objective match between parental behavior and child characteristics did not receive support in this study. The autonomous and controlled causality orientations failed to moderate the associations of either adolescent-reported or mother-reported maternal autonomy support with well-being, both at the level of betweenperson differences and at the level of within-person change. That is, adolescents with a high autonomous orientation do not derive greater well-being 
benefits when experiencing more autonomy-supportive parenting than do others, nor do they report a more pronounced increase in well-being when they experience greater autonomy support than usual. These findings are consistent with the notion that autonomy-supportive parenting contributes to the satisfaction of psychological needs that are universally important for children's well-being (Deci \& Ryan, 2000; Ryan \& Deci, 2017). In line with these claims, research increasingly demonstrates the benefits of autonomy-supportive parenting across cultures (Chirkov \& Ryan, 2001) and developmental periods (Bernier, Carlson, \& Whipple, 2010).

It would be very premature, however, to conclude that individual differences play no role whatsoever in effects of autonomy-supportive parenting (and to see the results as evidence for a strict universalistic perspective) because causality orientations could play a role in other ways. First, consistent with the notion of evocative child $\times$ environment transactions (Caspi \& Roberts, 2001), adolescents with different causality orientations may elicit different parental reactions. Adolescents high on autonomy may communicate more clearly to parents about their personal preferences, which would enable their parents to more easily consider these interests. Future longitudinal research could test this possibility that adolescents' causality orientations elicit more or less autonomy support (see also Jang, Kim, \& Reeve, 2016).

Second, consistent with the notion of reactive child $\times$ environment transactions (Caspi \& Roberts, 2001), adolescents' causality orientations may also affect their perception and interpretation of parental behavior (Deci \& Ryan, 1985; Hagger \& Chatzisarantis, 2011; Soenens et al., 2015). For instance, adolescents high on an autonomy orientation may interpret parental provision of choice more as an opportunity to pursue self-endorsed goals than do adolescents high on a controlled orientation (Mouratidis, Vansteenkiste, Sideridis, \& Lens, 2011). To examine such reactive processes, future research should aim to separate parents' actual behavior (i.e., what they actually do and say) from how it is perceived and appraised by adolescents, thereby for instance relying on observational measures of parenting or on vignettes describing actual parental behavior (e.g., Chen, Soenens, Vansteenkiste, Van Petegem, \& Beyers, 2016).

\section{Goodness of Fit as a Subjective Experience}

Different from an objective match between autonomy-supportive parenting and adolescents' personality, a subjective interpretation of goodness of fit involves adolescents' perception that their parents understand their personality and consider adolescents' personality in family interactions. As expected, we found evidence for rather systematic associations between 
autonomy-supportive parenting and subjectively felt goodness of fit, which is an association that emerged both at the level of between-person differences and at the level of within-person change across three waves. Associations were more pronounced when using adolescent reports of parenting compared to mother reports. Still, even when using maternal reports of parenting, the association was significant at the level of within-person change and marginally significant at the level of between-person differences. Moreover, subjectively felt goodness of fit played an intervening role in associations between autonomy-supportive parenting and adolescents' well-being at both levels. At the between-person level, our findings indicate that the reason why adolescents who perceive their mothers as more autonomy supportive report greater well-being is because they experience greater fit relative to other adolescents. At the within-person level, the findings suggest that the reason why ups and downs in adolescent-perceived or mother-reported autonomy support (relative to adolescents' baseline level of experienced autonomy support) go hand in hand with ups and downs in adolescent' well-being is because adolescents report greater experienced fit in periods when their mothers are more autonomy supportive.

These findings are consistent with the assumption that the basic attitude behind parental autonomy support involves an active interest in and respect for the child's frame of reference (Grolnick et al., 1997; Mageau et al., 2017). Because of their sincere curiosity for what is going on with their children, autonomy-supportive parents are likely to become quite well informed about their children's personal functioning and personality features. This knowledge is an important starting point in considering their children's personality in the process of child rearing (Assor, KanatMaymon, Keren-Pariente, \& Katz, 2020).

\section{Limitations and Directions for Future Research}

This study had a number of methodological limitations. First, because this was just a first study examining the role of causality orientations in effects of autonomy-supportive parenting, we did not have a point of reference to ensure sufficient statistical power a priori. A post hoc power analysis using Monte Carlo simulation showed that, whereas our study had sufficient power (i.e., over 80\%) to detect main effects of parenting at the level of intraindividual change, the power to detect cross-level interactions was low (i.e., well below 80\%). However, the results of such a post hoc power analysis are difficult to interpret because the lack of power may be due to the observed effects being actually small (Levine \& Ensom, 2001). Hence, future research may rely on larger samples to replicate the current results and may use the effects sizes obtained herein in an a priori power analysis. 
Related to the issue of statistical power, there was a lot of attrition. Although data were missing at random, ideally future studies will have a higher retention rate. Further, we focused only on maternal parenting, and our sample involved, on average, relatively well-adjusted adolescents with a fairly homogeneous background (i.e., traditional, two-parent families and mothers with rather high levels of education). More research may examine the generalizability of the current findings in more heterogeneous samples.

The low reliability of the mother-reported score for autonomysupportive parenting (see Table 1) is another limitation. Although it is not unusual to obtain lower reliability with a parent-reported score for parenting variables (e.g., Soenens, Vansteenkiste, Luyckx, \& Goossens, 2006), the findings with this scale need to be interpreted with some caution.

In addition to addressing the methodological limitations discussed thus far, future research could build on this study in substantive ways. Future research on the role of individual differences in autonomy-supportive parenting needs to go beyond an assessment of causality orientations and can include measures of adolescents' broader personality functioning (e.g., the Five Factor Model dimensions of personality). This is important because results from our multilevel analyses demonstrated that the strength of the association between adolescent-perceived autonomy-supportive parenting and well-being indeed differs between adolescents. The question remains, then, as to which factors in adolescents' functioning are associated with these individual differences.

Although our findings suggest that autonomy-supportive parents create a climate in which adolescents experience a subjective fit between their personality and the parents' behaviors, it is not clear at this point how these parents manage to do this. These specific ways in which autonomysupportive parents create conditions for goodness of fit may also differ depending on children's age. Future research that addresses this topic will ideally include detailed observations of how parental autonomy support manifests in response to children with different personality characteristics. To illustrate, it would be interesting to explore whether the type of choices and type of rationales for requests that autonomy-supportive parents provide, which are two key features of an autonomy-supportive style, would vary as a function of children's personality. Ultimately, the knowledge gained from these studies can be used to enrich parenting interventions with guidelines for how parents can adjust their interaction style to children's personality and temperament (Rettew, 2013; Shiner et al., 2012).

A final issue concerns the question of possible alternative pathways other than goodness of fit. On the basis of SDT, it has also been argued and shown that satisfaction of the basic psychological needs for autonomy, 
competence, and relatedness can explain the beneficial effects of autonomy-supportive parenting (e.g., Grolnick et al., 1991). Future research can address the question of how our findings regarding the intervening role of goodness of fit can be integrated with findings documenting the intervening role of psychological need satisfaction. Possibly, a sense of goodness of fit represents one important route through which adolescents experience more need satisfaction within parent-child relationships. For instance, when adolescents feel that their parents have an accurate view of the adolescents' personality and consider their personality, adolescents are more likely to feel a genuine sense of connection to their parents (i.e., relatedness satisfaction) and to feel that there is room to be who they really are (i.e., autonomy satisfaction). Most likely, experiences of need satisfaction in turn reinforce feelings of goodness of fit. A final possibility is that the experience of goodness of fit is a direct manifestation or byproduct of experienced need satisfaction, which yields the more powerful effect on well-being when entered simultaneously. Longitudinal research is ideally suited to further examine the dynamic interplay between parenting, goodness of fit, and the psychological needs.

\section{Conclusions}

Although the notion of goodness of fit has figured in the parenting literature for quite some time (Kiff, Lengua, \& Zalewski, 2011; Thomas \& Chess, 1977) and has been invoked to account for parenting by personality interactions (e.g., De Clercq, Van Leeuwen, De Fruyt, Van Hiel, \& Mervielde, 2008), the empirical work directly targeting the concept is limited. This study undertook an integrative attempt to study the relation between autonomysupportive parenting, as conceived within self-determination theory (Ryan \& Deci, 2017), and the literature on goodness of fit, thereby proposing two different interpretations. When interpreted in terms of a fairly literal match, no evidence was obtained. That is, maternal autonomy support was generally related to well-being, irrespective of individual differences in adolescents' personality-based motivational orientation. These findings suggest that the benefits of autonomy-supportive parenting are not limited to adolescents with personality characteristics that match an autonomy-supportive style, as would be assumed from a relativistic parenting perspective. When interpreted in terms of a subjective sense of goodness of fit, the findings were more promising, indicating that the very reason why autonomy-supportive parenting relates to greater well-being among adolescents is because it goes along with a greater subjective sense of fit. 


\section{References}

Assor, A., Kanat-Maymon, Y., Keren-Pariente, S., \& Katz, I. (2020). You should know me better: Parents' temperament-insensitivity has negative motivational effects on Bedouin and Jewish adolescents. Journal of Personality, 1-18. doi: 10.1111/jopy. 12532

Aunola, K., Viljaranta, J., Lehtinen, E., \& Nurmi, J. E. (2013). The role of maternal support of competence, autonomy and relatedness in children's interests and mastery orientation. Learning and Individual Differences, 25, 171-177. doi:10.1016/j.lindif.2013.02.002

Bernier, A., Carlson, S. M., \& Whipple, N. (2010). From external regulation to selfregulation: Early parenting precursors of young children's executive functioning. Child Development, 81, 326-339. doi:10.1111/j.1467-8624.2009.01397.x

Bornstein, M. H. (2015). Children's parents. In R. M. Lerner (Series Ed.) \& M. H. Bornstein \& T. Leventhal (Vol. Eds.), Handbook of child psychology and developmental science: Vol. 4. Ecological settings and processes in developmental systems (7th ed., pp. 55-132). Hoboken, NJ: Wiley.

Caspi, A., \& Roberts, B. W. (2001). Personality development across the life course: The argument for change and continuity. Psychological Inquiry, 12, 49-66. doi:10.1146/annurev.psych.55.090902.141913

Chen, B. W., Soenens, B., Vansteenkiste, M., Van Petegem, S., \& Beyers, W. (2016). Where do the cultural differences in dynamics of controlling parenting lie? Adolescents as active agents in the perception of and coping with parental behavior. Psychologica Belgica, 56, 169-192. doi:10.5334/pb.306

Chirkov, V. I., \& Ryan, R. M. (2001). Parent and teacher autonomy-support in Russian and US adolescents: Common effects on well-being and academic motivation. Journal of Cross-Cultural Psychology, 32, 618-635. doi:10.1177/ 0022022101032005006

Costa, S., Cuzzocrea, F., Gugliandolo, M. C., \& Larcan, R. (2016). Associations between parental psychological control and autonomy support, and psychological outcomes in adolescents: The mediating role of need satisfaction and need frustration. Child Indicators Research, 9, 1059-1076. doi:10.1007/s12187015-9353-Z

De Clercq, B., Van Leeuwen, K., De Fruyt, F., Van Hiel, A., \& Mervielde, I. (2008). Maladaptive personality traits and psychopathology in childhood and adolescence: The moderating effect of parenting. Journal of Personality, 76, 357-383. doi:10.1111/j.1467-6494.2007.00489.x

De Pauw, S. S. W., \& Mervielde, I. (2010). Temperament, personality and developmental psychopathology: A review based on the conceptual dimensions underlying childhood traits. Child Psychiatry \& Human Development, 41, 313-329. doi:10.1007/s10578-009-0171-8 
Deci, E. L., \& Ryan, R. M. (1985). The general causality orientations scale: Selfdetermination in personality. Journal of Research in Personality, 19, 109-134. doi:10.1016/0092-6566(85)90023-6

Deci, E. L., \& Ryan, R. M. (1987). The support of autonomy and the control of behavior. Journal of Personality and Social Psychology, 53, 1024-1037. doi:10. 1037/0022-3514.53.6.1024

Deci, E. L., \& Ryan, R. M. (2000). The "what" and "why" of goal pursuits: Human needs and the self-determination of behavior. Psychological Inquiry, 11, 227 268. doi:10.1207/s15327965pli1104_01

Diener, E., Emmons, R. A., Larsen, R. J., \& Griffin, S. (1985). The Satisfaction with Life Scale. Journal of Personality Assessment, 49, 71-75. doi:10.1207/ s15327752jpa4901_13

Grolnick, W. S., Deci, E. L., \& Ryan, R. M. (1997). Internalization within the family: The self-determination theory perspective. In J. E. Grusec \& L. Kuczynski (Eds.), Parenting and children's internalization of values: A handbook of contemporary theory (pp. 135-161). New York: Wiley.

Grolnick, W. S., Gurland, S. T., DeCourcey, W., \& Jacob, K. (2002). Antecedents and consequences of mothers' autonomy support: An experimental investigation. Developmental Psychology, 38, 143-155. doi:10.1037/0012-1649.38.1.143

Grolnick, W. S., Ryan, R. M., \& Deci, E. L. (1991). Inner resources for school achievement: Motivational mediators of children's perceptions of their parents. Journal of Educational Psychology, 83, 508-517. doi:10.1037/0022-0663.83.4.508

Hagger, M. S., \& Chatzisarantis, N. L. D. (2011). Causality orientations moderate the undermining effect of rewards on intrinsic motivation. Journal of Experimental Social Psychology, 47, 485-489. doi:10.1016/j.jesp.2010.10.010

Harter, S. (1988). Manual for the Self-Perception Profile for adolescents. Denver, CO: University of Denver.

Hu, L. T., \& Bentler, P. M. (1999). Cutoff criteria for fit indexes in covariance structure analysis: Conventional criteria versus new alternatives. Structural Equation Modeling, 6, 1-55. doi:10.1080/10705519909540118

Jang, H., Kim E. J., \& Reeve, J. (2016). Why students become more engaged or more disengaged during the semester: A self-determination theory dual-process model. Learning and Instruction, 43, 27-38. doi:10.1016/j.learninstruc. 2016.01.002

Joussemet, M., Landry, R., \& Koestner, R. (2008). A self-determination theory perspective on parenting. Canadian Psychology, 49, 194-200. doi:10.1037/ a0012754

Keijsers, L. (2016). Parental monitoring and adolescent problem behaviors: How much do we really know? International Journal of Behavioral Development, 40, 271-281. doi:10.1177/0165025415592515 
Kiff, C. J., Lengua, L. J., \& Zalewski, M. (2011). Nature and nurturing: Parenting in the context of child temperament. Clinical Child and Family Psychology Review, 14, 251-301. doi:10.1007/s10567-011-0093-4

Klimstra, T. A., Hale III, W. W., Raaijmakers, Q. A., Branje, S. J., \& Meeus, W. H. (2009). Maturation of personality in adolescence. Journal of Personality and Social Psychology, 96, 898-912. doi:10.1037/a0014746

Levine, M., \& Ensom, M. H. (2001). Post hoc power analysis: An idea whose time has passed? Pharmacotherapy: Journal of Human Pharmacology and Drug Therapy, 21, 405-409. doi:10.1592/phco.21.5.405.34503

Mackinnon, S. P., Kehayes, I. L., Clark, R., Sherry, S. B., \& Stewart, S. H. (2014). Testing the four-factor model of personality vulnerability to alcohol misuse: A three-wave, one-year longitudinal study. Psychology of Addictive Behaviors, 28, 1000-1012. doi:10.1037/a0037244

MacKinnon, D. P., Lockwood, C. M., Hoffman, J. M., West, S. G., \& Sheets, V. (2002). A comparison of methods to test mediation and other intervening variable effects. PsychologicalMethods, 7, 83-104.doi:10.1037/1082-989X.7.1.83

Mageau, G. A., Sherman, A., Grusec, J. E., Koestner, R., \& Bureau, J. S. (2017). Different ways of knowing a child and their relations to mother-reported autonomy support. Social Development, 26, 630-644. doi:10.1111/sode.12212

Manders, W. A., Scholte, R. H. J., Janssens, J., \& De Bruyn, E. E. J. (2006). Adolescent personality, problem behaviour and the quality of the parentadolescent relationship. European Journal of Personality, 20, 237-254. doi:10.1002/per.574

Mervielde, I., \& De Fruyt, F. (1999). Construction of the Hierarchical Personality Inventory for Children (HiPIC). In I. Mervielde, I. Deary, F. De Fruyt, \& F. Ostendorf (Eds.), Personality psychology in Europe: Proceedings of the Eighth European Conference on Personality Psychology (pp. 107-127). Tilburg, The Netherlands: Tilburg University Press.

Moller, A. C., Deci, E. L., \& Elliot, A. J. (2010). Person-level relatedness and the incremental value of relating. Personality and Social Psychology Bulletin, 36, 754-767. doi:10.1177/0146167210371622

Mouratidis, A., Vansteenkiste, M., Sideridis, G., \& Lens, W. (2011). Vitality and interest-enjoyment as a function of class-to-class variation in need-supportive teaching and pupils' autonomous motivation. Journal of Educational Psychology, 103, 353-366. doi:10.1037/a0022773

Muthén, L. K., \& Muthén, B. O. (1998-2012). Mplus user's guide (7th ed.). Los Angeles: Muthén \& Muthén.

Olesen, M. H. (2011). General causality orientations are distinct from but related to dispositional traits. Personality and Individual Differences, 51, 460-465. doi:10.1016/j.paid.2011.04.015 
Olesen, M. H., Thomsen, K., Schnieber, A. D., \& Tonnesvang, J. (2010). Distinguishing general causality orientations from personality traits. Personality and Individual Differences, 49, 538-543. doi:10.1013/j.paid.2009. 11.032

Preacher, K. J., Zyphur, M. J., \& Zhang, Z. (2010). A general multilevel SEM framework for assessing multilevel mediation. Psychological Methods, 15, 209-233. doi:10.1037/a0020141

Reeve, J. (2013). How students create motivationally supportive learning environments for themselves: The concept of agentic engagement. Journal of Educational Psychology, 105, 579-595. doi:10.1037/a0032690

Rettew, D. (2013). Child temperament: New thinking about the boundary between traits and illness. New York: W. W. Norton.

Roth, G., Assor, A., Niemiec, C. P., Ryan, R. A., \& Deci, E. L. (2009). The emotional and academic consequences of parental conditional regard: Comparing conditional positive regard, conditional negative regard, and autonomy support as parenting practices. Developmental Psychology, 45, 1119-1142. doi:10.1037/ a0015272

Ryan, R. M., \& Deci, E. L. (2000). Self-determination theory and the facilitation of intrinsic motivation, social development, and well-being. American Psychologist, 55, 68-78. doi:10.1037/0003-066x.55.1.68

Ryan, R. M., \& Deci, E. L. (2017). Self-determination theory: Basic psychological needs in motivation, development and wellness. New York: Guilford Press.

Ryan, R. M., \& Frederick, C. M. (1997). On energy, personality and health: Subjective vitality as a dynamic reflection of well-being. Journal of Personality, 65, 529-565. doi:10.1111/j.1467-6494.1997.tb00326.x

Ryan, R. M., Soenens B., \& Vansteenkiste, M. (2019). Reflections on self-determination theory as an organizing framework for personality psychology: Interfaces, integrations issues, and unfinished business. Journal of Personality, 87, 115-145. doi:10.1111/jopy.12440

Seifer, R., Dickstein, S., Parade, S., Hayden, L. C., Magee, K. D., \& Schiller, M. (2014). Mothers' appraisal of goodness of fit and children's social development. International Journal of Behavioral Development, 38, 86-97. doi:10.1177/0165025413507172

Sheldon, K. M., Cheng, C., \& Hilpert, J. (2011). Understanding well-being and optimal functioning: Applying the Multilevel Personality in Context (MPIC) model. Psychological Inquiry, 22, 1-16. doi:10.1080/1047840x.2011.532477

Shiner, R. L., Buss, K. A., McClowry, S. G., Putnam, S. P., Saudino, K. J., \& Zentner, M. (2012). What is temperament now? Assessing progress in temperament research on the twenty-fifth anniversary of Goldsmith et al. (1987). Child DevelopmentPerspectives, 6,436-444.doi:10.1111/j.1750-8606.2012.00254.x 
Soenens, B., Berzonsky, M. D., Vansteenkiste, M., Beyers, W., \& Goossens, L. (2005). Identity styles and causality orientations: In search of the motivational underpinnings of the identity exploration process. European Journal of Personality, 19, 427-442. doi:10.1002/per.551

Soenens, B., Deci, E. L., \& Vansteenkiste, M. (2017). How parents contribute to children's psychological health: The critical role of psychological need support. In L. Wehmeyer, T. D. Little, S. J. Lopez, K. A. Shogren, \& R. Ryan (Eds.), Handbook on the development of self-determination (pp. 171-187). New York: Springer.

Soenens, B., Vansteenkiste, M., \& Beyers, W. (2019). Parenting adolescents. In M. H. Bornstein (Ed.), Handbook of parenting: Vol. 1. Children and parenting (3rd ed., pp. 101-167). New York: Routledge.

Soenens, B., Vansteenkiste, M., Lens, W., Luyckx, K., Goossens, L., Beyers, W., \& Ryan, R. M. (2007). Conceptualizing parental autonomy support: Adolescent perceptions of promotion of independence versus promotion of volitional functioning. Developmental Psychology, 43, 633-646. doi:10.1037/ 0012-1649.43.3.633

Soenens, B., Vansteenkiste, M., Luyckx, K., \& Goossens, L. (2006). Parenting and adolescent problem behavior: An integrated model with adolescent self-disclosure and perceived parental knowledge as intervening variables. Developmental Psychology, 42, 305-318. doi:10.1037/0012-1649.42.2.305

Soenens, B., Vansteenkiste, M., \& Van Petegem, S. (2015). Let us not throw out the baby with the bathwater: Applying the principle of universalism without uniformity to autonomy-supportive and controlling parenting. Child Development Perspectives, 9, 44-49. doi:10.1111/cdep.12103

Thomas, A., \& Chess, S. (1977). Temperament and development. New York: Brunner/Mazel.

Thomas, A., Chess, S., \& Birch, H. (1968). Temperament and behavior disorders in children. New York: New York University Press.

Van Aken, C., Junger, M., Verhoeven, M., Van Aken, M. A. G., \& Dekovic, M. (2007). The interactive effects of temperament and maternal parenting on toddlers externalizing behaviours. Infant and Child Development, 16, 553-572. doi:10.1002/icd.529

Van der Giessen, D., Branje, S., \& Meeus, W. (2014). Perceived autonomy support from parents and best friends: Longitudinal associations with adolescents' depressive symptoms. Social Development, 23, 537-555. doi:10.1111/ sode. 12061

Van Leeuwen, K. G., Mervielde, I., Braet, C., \& Bosmans, G. (2004). Child personality and parental behavior as moderators of problem behavior: Variableand person-centered approaches. Developmental Psychology, 40, 1028-1046. doi:10.1037/0012-1649.40.6.1028 
Vansteenkiste, M., Niemiec, C., \& Soenens, B. (2010). The development of the five mini-theories of self-determination theory: An historical overview, emerging trends, and future directions. In T. Urdan \& S. Karabenick (Eds.), Advances in motivation and achievement (Vol. 16, pp. 105-166). Bingley, England: Emerald.

Vansteenkiste, M., \& Soenens, B. (2015). Vitamines voor groei: Ontwikkeling voeden vanuit de Zelf-Determinatie Theorie [Vitamins for growth: Feeding development from the self-determination theory]. Gent, Belgium: Acco.

Vasquez, A. C., Patall, E. A., Fong, C. J., Corrigan, A. S., \& Pine, L. (2016). Parent autonomy support, academic achievement, and psychosocial functioning: A meta-analysis of research. Educational Psychology Review, 28, 605-644. doi:10.1007/s10648-015-9329-z

Wichstrom, L. (1995). Harter's Self-Perception Profile for Adolescents: Reliability, validity, and evaluation of the question format. Journal of Personality Assessment, 65, 100-116. doi:10.1207/s15327752jpa6501_8 